\title{
UNCOMMON INTESTINAL MALROTATION IN ADULT PATIENTS - PRESENTATION OF 4 CASES
}

\author{
Muhammedoglu Bahtiyar, ${ }^{1}$ Topuz Sezgin, ${ }^{2}$ Saracoglu Mustafa, ${ }^{3}$ \\ Koktas Suleyman, ${ }^{2}$ Pircanoglu Eyup Mehmet, ${ }^{2}$ Kara Turgay ${ }^{4}$ \\ ${ }^{1}$ Department of Gastroenterologic Surgery, Necip Fazsl State Hospital, Kahramanmaras, Turkey \\ ${ }^{2}$ Department of Surgery, Necip Fazıl State Hospital, Kahramanmaras, Turkey \\ ${ }^{3}$ Department of Gastroenterologic Surgery, University of Health Science, \\ Konya Trainning and Research Hospital, Konya, Turkey \\ ${ }^{4}$ Department of Radiology, University of Health Science, \\ Konya Trainning and Research Hospital, Konya, Turkey
}

Primljen/Received 28. 01. 2019. god.

Abstract: Rotation anomalies are usually anomalies seen in children. It is a rare condition in adults. In this article, 4 cases are presented. In the first case, reverse rotation anomaly and appendicitis perforation were detected in a patient who had laparotomy at the age of 22 with acute abdomen. It is a unique condition that the patient had a history of previous appendectomy. Ladd band may be the cause of acute abdomen due to ileus. The patient in our second case presented a concurrent biliary stone and malrotation with Ladd band. In addition, two elderly patients who underwent hemicolectomy due to intestinal ileus caused by malrotation were presented with literature review.

Key words: Midgut, Intestinal Malrotation, Volvulus, Imaging, Surgery.

\section{INTRODUCTION}

Any failure in normal embryological $270^{\circ}$ counter clockwise intestinal rotation around the superiormesenteric vessels is considered to be malrotation. Duodenum and jejunum is situated on the rightside of columna vertebralis in these patients. This anomaly causes intermittent episodes of acute events such as gastrointestinal obstruction or volvulus (1). Midgut malrotation occurs in about 1 out of 500 newborns. The incidence of intestinal malrotation in adults is about $0.2 \%$ (2). Asymptomatic cases are usually diagnosed coincidentally during another surgery. The presence of narrow mesenteric root with a long pedicle and having a mobile colon segment are among the predisposing factors $(3,4,5) .6 \%$ of the neonatal obstruction is cau-
Prihvaćen/Accepted 16. 04. 2019. god.

sed by rotation anomalies (6). Rotation anomalies seen in the large intestine most commonly affects the sigmoid colon as $40 \%$ (7). Peritoneal bands are often associated with intestinal malrotation and divided to 4 types. In type 1; there is an abnormal band extending from the caecum to the right upper quadrant and crosses the 2 nd and 3rd parts of the duodenum and compresses to the duodenum. This is called Ladd's band (8).

Double-contrast enhanced computed tomography (CT), magnetic resonance imaging (MRI), angiography and sometimes diagnostic laparotomy are used for diagnosis. Diagnostic laparoscopic imaging is indicated for patients with intestinal malrotation in case of upper gastrointestinal system uncertainty.

Treatment of intestinal malrotation was first described in 1936 by William E. Ladd, the great pediatric surgeon in North America, and is currently the basis for malrotation therapy (9). Open Ladd's Procedure consists of, transverse incision or midline laparotomy, evisceration of intestinal contents, detorsion counter-clockwise if volvulus is present, resection grossly necrotic bowel, consideration second look laparotomy if questionable viability, releasing of Ladd's cecal bands, broadening the small intestine mesentery, profilactic appendectomy, placement small bowel on right and colon on left (9). Laparoscopic Ladd procedure is a technique applied for intestinal malrotation in adults in order to eliminate chronic symptoms (9). As a less invasive and cosmetically attractive technique, the use of single-incision laparoscopic surgery (SILS) have increased. The expected advantages SILS include less pain, recovery time, and less trocar injury rates $(10,11,12)$. 


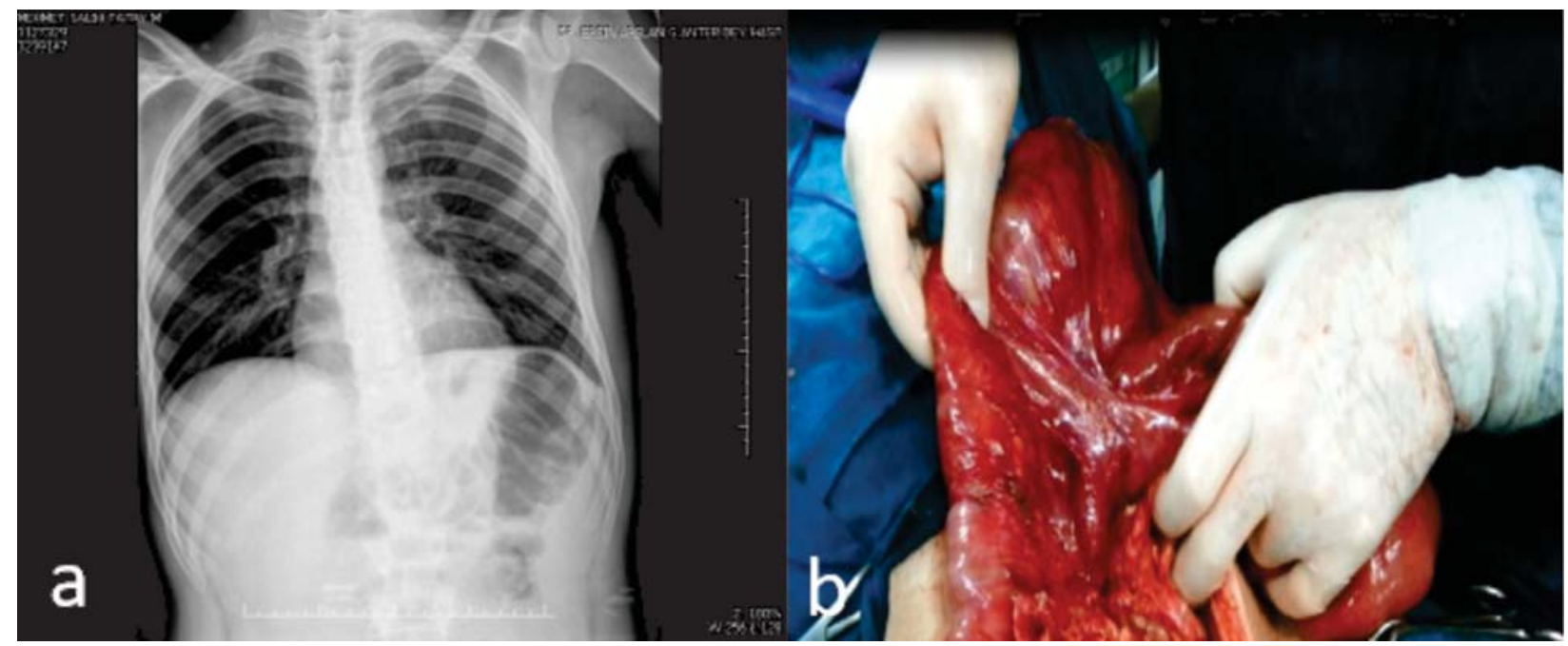

Figure 1. a) X ray shows large bowel on left part of abdomen b) Patient's ladd operation was performed. Mesenteric root was detorsioned

We present four cases of adult malrotation who presented with chronic abdominal pain and/or ileus.

\section{CASE 1}

A 22-year-old Syrian male, who had an appendectomy operation history 1 week ago abroad, admitted to the emergency department of the public hospital. The pain continued after the appendectomy operation. In physical and laboratory examinations, colonic obstruction findings and lokocytosis were detected. Ultrasonography (US) revealed free fluid in the abdomen. Plain radiography of abdomen revealed large bowels clustering on left (Figure 1a). The patient was considered to have secondary adhesions and ileus. Laparotomy was decided due to acute abdomen findings. During the operation, it was seen that all the loops between treitz ligament and sigmoid colon turned on theirselves and the mesenteric circulation was disrupted. It was seen that the cecum was atypically in the left lower quadrant and duodenojejunal junction was on the right side of abdomen. Appendix had not been taken and was perforated from the tip. Abdomen was looking infected and dirty All the small intestines were volvulized and edematous and hyperemic. It was considered as complete nonrotation anomaly. The patient underwent open Ladd's operation; bowel loops were detorsed in a counterclockwise direction and Ladd bands which are crossing from right paracolic area to the right colon and cecum were lysed. Blood flow in the mesentery was checked. There was no blood flow impairment. Appendectomy was performed (Figure 1b). The bowel loops were replaced. At the end of operation small bowel loops were in the right abdomen and the cecum and other colon segments were in the left abdomen. The postoperative period was uneventful.

\section{CASE 2}

A 59-year-old female patient was admitted to the hospital with abdominal pain, intermittent nausea, vomiting and jaundice for 1 week. Pain has been present for 5-6 years, but recently the severity and frequency of attacks have increased gradually. On physical examination, there were no signs of abdominal distention. In abdominal US, cholelithiasis and choledocholithiasis were observed and magnetic resonance cholangiopancreatography (MRCP) was recommended. In the MRCP, the common bile duct was $2 \mathrm{~cm}$ wide and 1.5 $\mathrm{cm}$ stone was observed in the lumen (Figure 2a, 2b). Direct abdominal radiography and chest radiography were normal. Because the patient was managed with the diagnosis of cholelithiasis and choledocholithiasis, abdominal tomography was not requested. Since the view was primarily compatible with choledocholithiasis, Endoscopic Retrograde Cholangio-Pancreatography (ERCP) was planned to the patient. Since the stone was $1.5 \mathrm{~cm}$, the ERCP procedure was determined as a "difficult stone" and the open surgical consent form was signed for the possibility of failure of the procedure. Although sphincterotomy and endoscopic papillary large balloon dilation (ELBD) were performed in ERCP, stone could not be removed. Cholangiography confirmed the $1.5 \mathrm{~cm}$ stone in common bile duct (choledoch). In this case, open surgery decision was taken. The right subcostal incision (Kocher's) was used to enter into the abdomen. The small bowel was located on the right and the large intestine was located on the left. A fibrotic band, Ladd band, extending from the subhepatic area compressing to the duodenum was observed. The diagnosis was complete nonrotation anomaly. The common bile duct was dilated over $2 \mathrm{~cm}$. Choledochotomy, choledochoduodenostomy, cholecystectomy and 


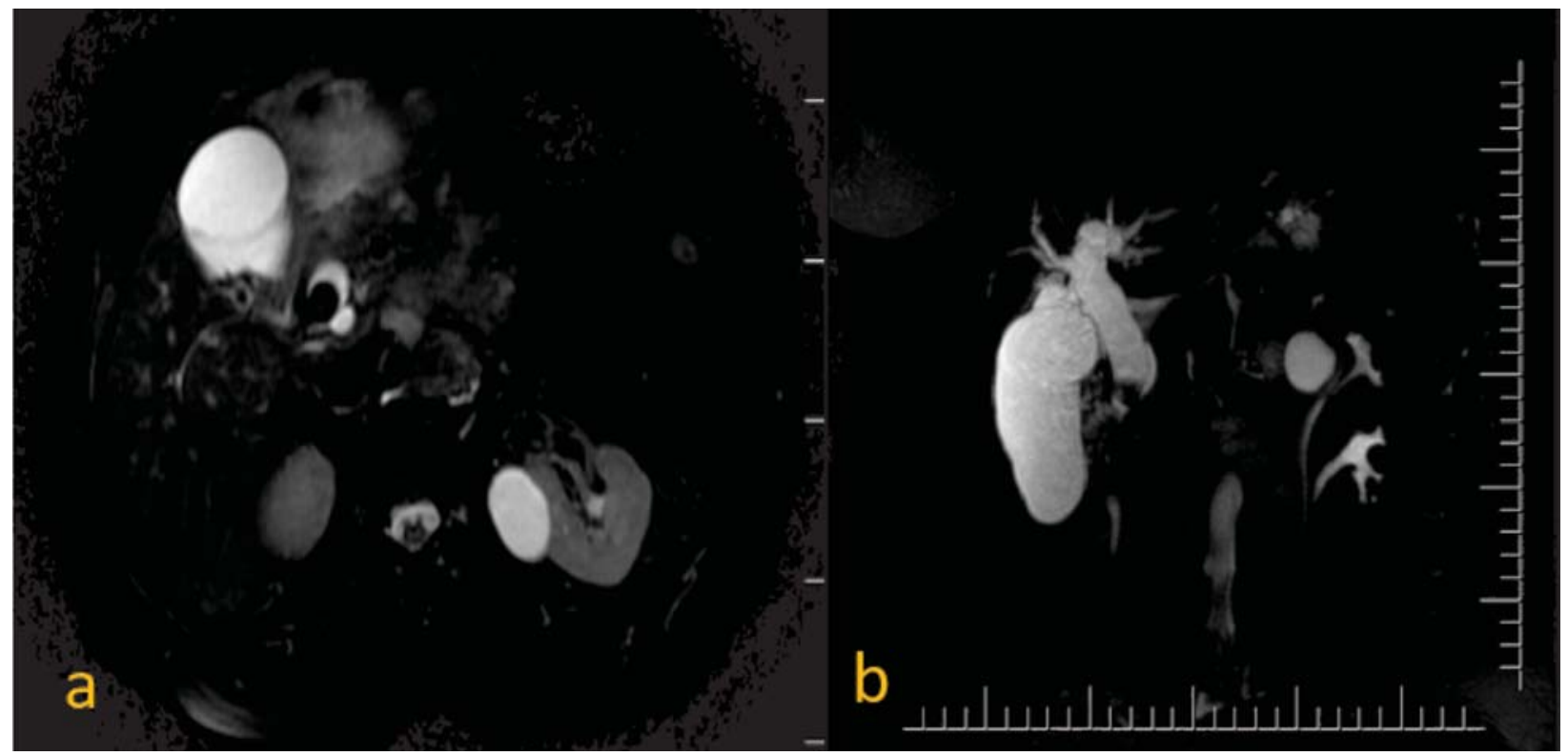

Figure 2. MRCP shows stone in common bile duct a) axial b) coronal view

Ladd band excision were decided. The duodenum was cohered and the Ladd band over the duodenum was excised. Cholecystectomy and choledochoduodenostomy were performed. The bowel loops were left in original malrotated positions. The small intestine was placed on the right and the large intestine was placed to the left and a drain was placed in the subhepatic area and the operation was terminated. The postoperative period was uneventful.

\section{CASE 3}

A seventy-four-year-old female patient was admitted to the emergency room with abdominal pain, intermittent nausea, vomiting and jaundice in the last 2 weeks. She had abdominal distention and epigastric defense. She had occasionally abdominal pain and vomiting on medical history. Abdominal x-ray showed that the right colon was on the left half of the abdomen (Figure 3a). Leukocytosis, mild increased total and direct bilirubin and electrolyte imbalance were seen on labarotory test. Laparotomy was performed with the diagnosis of ileus. At exploration the cecum was malrotated, in left upper quadrant. But duodenojejunal junction was in the original place. Treitz ligament was formed as usual. The cecocolic malrotation was diagnosed. The mesenteric root was volvulized and purple in color consistent with ischemia. When right colon and ileal segments were detorsed in a counterclockwise direction Ladd's band was seen over hepatic flexure, that crossing from right retroperiton to the cecum, which is in the left upper abdomen. Ladds procedure was applied to the patient (Figure 3b). After detorsion of mesentery, the color of the midgut colon didn't changed and necrosis was diagnosed. Therefore exten-

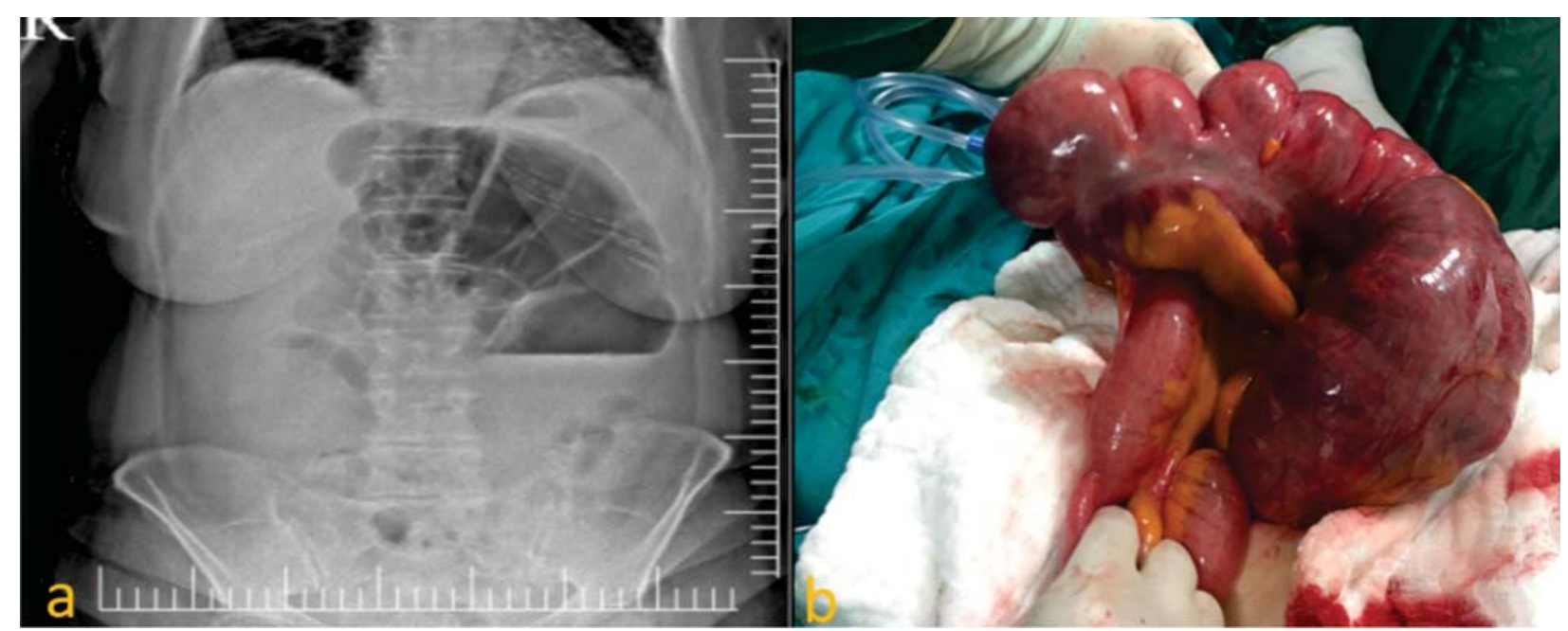

Figure 3. X ray, colon was on the left half of the abdomen. b) Ladd's Procedure, detosion of mesenteric root which seemed ischemic 
ded right hemicolectomy was performed. The postoperative period was uneventful and she was discharged on postoperative day 9 th.

\section{CASE 4}

A 84-year-old female patient was admitted to the emergency department of the public hospital. She had abdominal pain for 1 week and fecaloid vomiting. She had fever, hypotension and tachycardia on physical examination, consisting with sepsis. On laboratory test leukocytosis, mild anemia and electrolyte imbalance were seen. Findings of colonic obstruction were detected in the examinations. US revealed free fluid in the abdomen. Computed Tomography (CT) revealed enlarged intestinal loops with air-fluid levels (Figure 4). Acute laparotomy decision was settled because of acute abdomen findings. During the operation, it was observed that all the loops between the Treitz and sigmoid colon had turned on itself and the circulation of the mesentery was disrupted. Bowel loops were volvulized. It was seen that the caecum was in the lower left quadrant. The small bowel segments were in the right abdomen. Complete nonrotation anomaly was considered.

Infected fluid was seen in the abdomen. All the small intestines were edematous and hyperemic. The patient underwent Ladd's procedure operation. The root of the mesentery was derotated by turning counterclockwise. Blood flow in the mesentery was checked. Serosa of the caecum was purple and blood supply was impaired. It was observed that the circulation was not improved by detorsion therefore right hemicolectomy was performed. Abdomen was washed, the drain was placed and closed. The postoperative period was uneventful and she was discharged.

\section{DISCUSSION AND CONCLUSION}

Intestinal malrotation is considered a rare entitiy in adults. But Durkin et al (13) pointed out that intestinal malrotation in adults is diagnosed almost as often in adults as in children. Also it has a diagnostic dilemma in adulthood. Adult patients with intestinal malrotation can present with acute and chronic clinical conditions. Patients seek remedy for diverse non-specific complaints such as vague abdominal cramps, nausea, emesis, intermittent diarrhea, hematochezia, constipation and weight loss. Patients with these chronic non-specific symptoms apply to hospitals frequently but it takes a long time to make a true diagnosis. A high index of clinical suspicion is necessary. On occasions adult patients with rotation anomaly can present with abdominal catastrophe such as midgut volvulus, intestinal ischaemia and gangrene. So general surgeons should become familiar with intestinal malrotation symptoms and its treatment.

It is suggested that the gold standart imaging modalities for diagnosis of intestinal malrotation are upper gastrointestinal (UGI) contrast series and CT imaging with oral and IV contrast agent. UGI is suitable for children. In adult patients typical findings of CT scans are reversed relation of superior mesenteric artery (SMA) and superior mesenteric vein (SMV), whirlpool sign, small bowel loops in the right abdomen, a lack of visualization of ceacum in the right iliac fossa, dilatation of various duodenal loops and duodenojejunal loops to the right (corkscrew sign).

Treatment of intestinal malrotation was first described in 1936 by William E. Ladd, the great pediatric surgeon in North America, and is currently the basis for malrotation therapy (9). Open Ladd's Procedure consists of, transverse incision or midline laparotomy,

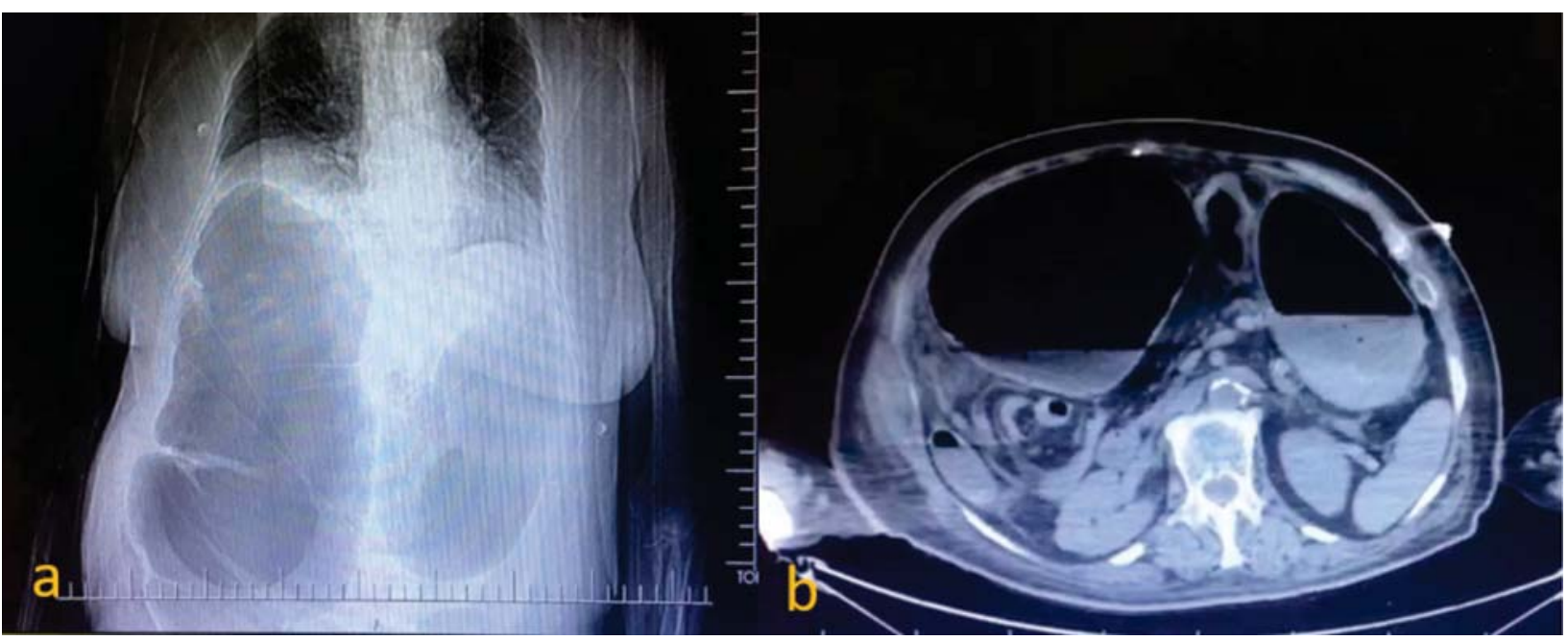

Figure 4. a) Abdomen X ray shows caecum in the lower left quadrant and enlarged colon segments on right. b) contrast enhanced-CT revealed enlarged intestinal loops with air-fluid levels 
evisceration of intestinal contents, detorsion counter-clockwise if volvulus is present, resection grossly necrotic bowel, consideration second look laparotomy if questionable viability, releasing of Ladd's cecal bands, broadening the small intestine mesentery, profilactic appendectomy, placement small bowel on right and colon on left (9). Also laparoscopic Ladd procedure is a technique applied for intestinal malrotation in adults in order to eliminate chronic symptoms.

Our cases draw attention by several points. Three of four patients were diagnosed with complete nonrotation anomaly, the most common presentation. The remaining rotation anomaly was isolated isolated cecocolic malrotation.

In our first case, a 22-year-old patient who underwent laparotomy with the diagnosis of acute abdomen, had complete nonrotation anomaly and appendicitis perforation. It is a unique condition that the patient had a history of previous appendectomy. Whatever the patient's anamnesis, the suspicious approach has always been life-saving.

As is known in the literature, Ladd bands may be the cause of acute abdomen due to ileus. In our second case, a gallstone was found in the gallbladder accompanying Ladd band. Did the Ladd band cause choledocholithiasis as a result of chronic obstruction of the duodenum and common bile duct or was it incidental? The presence of ladd bands may lead to compression of the duodenum, small bowel; volvulus, ischemia and necrosis. The presentation is difficult due to rarety in the elderly. According to the literature, most of the patients were treated by laparotomy and only a few cases were operated laparoscopically (10). John Vassaur et al. claimed that the SILS technique in the intestinal malrotation is successful and reliable when performed by an experienced surgeon (11). According to the study of Lodwick et al. patients who underwent laparoscopic Ladd procedure had short hospital stay and a decrease rate in complications such as bowel obstruction, but post-surgical volvulus incidence increased (12). It has not been established that small bowel fixation in operation prevents the volvulus in patients with intestinal malrotation. In the pediatric series, this complication occurs between $10-15 \%$ of cases after Ladd procedure.

In conclusion, eventhough the use of preoperative imaging modalities helps to diagnose the rare reasons of intestinal malrotation, sometimes the diagnosis is made only during surgery. The Ladd's procedure is safely performed in the surgical treatment of intestinal malrotation. After the Ladd process, the intestines should be left in place. Ileus is a known complication of intestinal malrotation. In case 2 , did Ladd band cause choledocholithiasis as a result of chronic obstruction of the duodenum and common bile duct or is it incidental? We can find the answer to this question by following other case reports.

Conflict of Interests: The authors declare that there are no conflicts of interest related to this article.

Funding: This research did not receive any specific grant from funding agencies in the public, commercial, or not-for-profit sectors.

\section{Licensing}

This work is licensed under a Creative Commons Attribution 4.0 International (CC BY 4.0) License.

\title{
Sažetak
}

\author{
NEUOBIČAJENA CREVNA MALROTACIJA \\ KOD ODRASLIH PACIJENATA - PRIKAZ 4 SLUČAJA \\ Muhammedoglu Bahtiyar, ${ }^{1}$ Topuz Sezgin, ${ }^{2}$ Saracoglu Mustafa, ${ }^{3}$ \\ Koktas Suleyman, ${ }^{2}$ Pircanoglu Eyup Mehmet, ${ }^{2}$ Kara Turgay ${ }^{4}$ \\ ${ }^{1}$ Department of Gastroenterologic Surgery, Necip Fazsl State Hospital, Kahramanmaras, Turkey \\ ${ }^{2}$ Department of Surgery, Necip Fazıl State Hospital, Kahramanmaras, Turkey \\ Department of Gastroenterologic Surgery, University of Health Science, \\ Konya Trainning and Research Hospital, Konya, Turkey \\ ${ }^{4}$ Department of Radiology, University of Health Science, Konya Trainning and Research Hospital, Konya, Turkey
}

Rotacione anomalije su obično anomalije koje se sreću kod dece. To je retko stanje kod odraslih. U ovom radu su prikazana 4 slučaja. U prvom slučaju, anomalija obrnute rotacije i perforacija apendiksa otkriveni su kod pacijenta koji je imao laparotomiju u dobi od 22 godine sa znacima akutnog abdomena. To je jedinstven slučaj da je pacijent imao istoriju prethodne apendektomije. Ladova priraslica može biti uzorok akutnog ab- domena zbog ileusa. Pacijent je u našem drugom slučaju imao bilijarnu kalkulozu i malrotaciju sa Ladovom priraslicom. Pored toga, dva starija pacijenta koja su bila podvrgnuta hemikolektomiji usled crevnog ileusa izazvanog malrotacijom, prikazana su u pregledu literature.

Ključne reči: srednje crevo, intestinalna malrotacija, Volvulus, operacija. 


\section{REFERENCES}

1. Haak BW, Bodewitz ST, Kuijper CF, de Widt-Levert LM. Intestinal malrotation and volvulus in adult life.. Int J Surg Case Rep. 2014; 5(5): 259-61.

2. Sheikh F, Balarajah V, Ayantunde AA. Recurrent intestinal volvulus in midgut malrotation causing acute bowel obstruction: A case report. World J Gastrointest Surg. 2013; 5(3): 43-6.

3. Gunsar C, Karaca I, Sencan A, Ceylan H, Mir E. Clinical presentation and radiographic identification of intestinal rotation anomalies in symptomatic neonates. Journal of the Turkish Association of Pediatric Surgeons. 2002; 16(1): 12-5.

4. Ford EG, Senac MOJr, Srikanth MS, Weitzman JJ. Malrotation of the intestine in children. Ann Surg.1992; 215(2): 172-8.

5. Powell DM, Othersen HB, Smith CD. Malrotatiton of the intestine in chidren. The effect of age on presentatiton and therapy. J.Pediatr Surg. 1989; 24(6): 777-80.

6. Stockmann PT. Maltoration. In: Oldham KT, Colombani PM, Foglia RP, Skiner MA. Principles and practice of pediatric surgery.(editörden). Philadelphia: Lippincott Williams and Wilkins, 2005: 1283-96.

\section{Correspondence to/Autor za korespondenciju}

\section{Turgay Kara}

Department of Radiology, University of Health Science, Konya Trainning and Research Hospital, Konya, Turkey email: attrgykr@gmail.com
7. Yaseen ZH, Watson RE, Dean HA, Wilson ME.. Case report: transverse colon volvulus in a patient with Clostridium difficle pseudomembranous colitis. Am J Med Sci. 1994; 308(4): 247-50.

8. Tanrıkulu Y, Tanrikulu CS, Temiz A, Karaman S, Akalp SO. Intestinal malrotation in an adult patient. Yeni Tip Derg. 2014; 31(2): 125-7.

9. Panda N, Bansal NK, Narasimhan M, Ardhanari R. Laparoscopic correction of intestinal malrotation in adult. J Minim Access Surg. 2014; 10(2): 90-2.

10. Bimbaum DJ, Geffroy Y, Goin G, Balandraud P. Left side appendicitis with midgut malrotation in an adult. J Surg Tech Case Rep. 2013; 5(1): 38-40.

11. Vassaur J, Vassaur H, Buckley FP. Single-Incision laparoscopic Ladd's procedure for intestinal malrotation JSLS. 2014; 18(1): 132-5.

12. Lodwick DL, Minneci PC, Deans KJ. Current surgical management of intestinal rotational abnormalities. Curr Opin Pediatr. 2015; 27(3): 383-8.

13. Durkin ET, Lund DP, Shaaban AF, Schurr MJ, Weber SM. Age related differences in diagnosis and morbidity of intestinal malrotation. J Am Coll Surg. 2008; 206 (4): 658-63. 